\title{
Hyperbilirubinemia Is a Significant Indicator for the Severity of Acute Appendicitis
}

\author{
Young Ran Hong, Chul-Woon Chung, Jong Woo Kim, Chang Il Kwon', Dae Ho Ahn, Sung Won Kwon, \\ Seong Ki Kim \\ Departments of Surgery and ${ }^{1}$ Gastroenterology, Bundang CHA Hospital, CHA University College of Medicine, Seongnam, Korea
}

Purpose: This study aims to reveal more effective clinical or laboratory markers for the diagnosis of acute appendicitis and to score the severity based on a sufficiently large number of patients with acute appendicitis.

Methods: We identified 1,195 patients with acute appendicitis after excluding those with other causes of hyperbilirubinemia among the 1,271 patients that underwent a laparoscopic or an open appendectomy between 2009 and 2010. A retrospective chart review of the medical records, including laboratory and histologic results, was conducted. We then analyzed the data using univariate and multivariate analyses.

Results: Among the 1,195 patients, a laparoscopic appendectomy was performed in 685 cases $(57.32 \%)$, and an open appendectomy was performed in 510 cases $(42.68 \%)$. The univariate analysis demonstrated significant differences for white blood cell count $(\mathrm{P}<0.0001)$, segmented neutrophils $(\mathrm{P}=0.0035)$, total bilirubin $(\mathrm{P}<0.0001)$, and systemic inflammatory response syndrome (SIRS) score between groups $(\mathrm{P}<0.0001)$. The multivariate analysis demonstrated that total bilirubin (odds ratio, 1.772; 95\% confidence interval, 1.320 to 2.379; $\mathrm{P}=0.0001$ ) and SIRS score (odds ratio, 1.583; 95\% confidence interval, 1.313 to $1.908 ; \mathrm{P}<0.0001$ ) have statistically significant diagnostic value for perforated appendicitis.

Conclusion: Hyperbilirubinemia is a statistically significant diagnostic marker for acute appendicitis and the likelihood of perforation.

Keywords: Appendicitis; Appendicitis, Perforated; Appendectomy; Hyperbilirubinemia

\section{INTRODUCTION}

Acute appendicitis is one of the most common acute surgical conditions of the abdomen. Since the first historical report of an appendectomy in France and England, the disease characteristics have come to be better known and more accurate diagnostic tools have been developed $[1,2]$. Aside from symptomatology and specific physical examination findings, ultrasonography and computed tomography (CT) scans have become the most useful tools, with

Received: August 14, 2012 - Accepted: October 18, 2012

Correspondence to: Chul-Woon Chung, M.D.

Department of Surgery, Bundang CHA Hospital, CHA University College of

Medicine, 59 Yatap-ro, Bundang-gu, Seongnam 463-712, Korea

Tel: +82-31-780-5250, Fax: +82-31-780-5259

E-mail:wehrwolf@cha.ac.kr

(C) 2012 The Korean Society of Coloproctology

This is an open-access article distributed under the terms of the Creative Commons Attribution NonCommercial License (http://creativecommons.org/licenses/by-nc/3.0) which permits unrestricted non-

commercial use, distribution, and reproduction in any medium, provided the original work is properly cited accuracies up to 85 to $99 \%$ [3-6]. However, as radiological examinations can be very costly and time-consuming, much interest exists in finding ways to diagnose and estimate the extent of acute appendicitis before relying on radiological examinations. Scoring systems such as the Alvarado Score and the Appendicitis Inflammatory Response Score have been devised to assist, along with the clinical characteristics and the usual laboratory analyses, in the diagnosis [7-13]. These scores are based on clinical presentations, leukocytosis and/or C-reactive protein, and they focused on the diagnostic assessment of appendicitis in a primary clinical setting.

Recently, some institutions have reported studies on the value of serum bilirubin for diagnosing acute appendicitis [14-16]. Hyperbilirubinemia has often been noted not only in appendicitis but also in other inflammatory conditions of the abdomen, suggesting that a certain relationship might exist between bacteria and serum bilirubin $[17,18]$. The studies that suggest this were based on relatively small population groups and were mainly focused on the predictive value of hyperbilirubinemia for the diagnosis of perforated appendicitis. Our study aims to determine whether 
hyperbilirubinemia reflects the severity of acute appendicitis based on a sufficiently large number of patients with acute appendicitis.

\section{METHODS}

\section{Patient population}

Among a total number of 1,271 patients that underwent an appendectomy due to acute appendicitis between January 2009 and December 2010, 1,195 patients were enrolled in the study. The patients with possible hyperbilirubinemia of other origins were excluded after application of exclusion criteria (Table 1). The appendectomy was performed either a laparoscopic or an open appendectomy.

The eligible patients were categorized into the following groups based on the final pathologic reports for the appendix and on the surgical findings: group 1, nonspecific inflammatory changes; group 2, acute suppurative changes; group 3, gangrenous and/or necrotic changes; group 4, perforated appendicitis [19]. Clinically, these four groups were simplified into two groups (i.e., nonperforated [groups 1 and 2] and perforated [groups 3 and 4]).

The possible factors that could be representative parameters were selected from preoperative laboratory results for each patient. The clinicopathological characteristics and laboratory values for each group were compared to each other. The standard values were

Table 1. Exclusion criteria

\begin{tabular}{l}
\hline Exclusion criteria \\
\hline Alcoholism \\
Acute hepatitis (viral, drug, and unknown) \\
Chronic liver disease \\
Gilbert syndrome \\
Dubin-Johnson syndrome \\
Benign recurrent intrahepatic cholestasis \\
Other documented biliary, hemolytic, or liver disease associated with hyperbiliru \\
binemia
\end{tabular}

given based on the reference of our institute as follows: white blood cell (WBC), 4.0 to $10.0 \times 10^{3} / \mu \mathrm{L}$; segmented neutrophils (segs), 43 to $75 \%$; banded neutrophils (bands), $\leq 0 \%$; aspartate aminotransferase (AST), 10 to $40 \mathrm{IU} / \mathrm{L}$; alanine aminotransferase (ALT), 5 to $40 \mathrm{IU} / \mathrm{L}$; and total bilirubin, $\leq 1.2 \mathrm{mg} / \mathrm{dL}$. The systemic inflammatory response syndrome (SIRS) score was calculated from the admission laboratory data on each patient because it had been used by other authors $[20,21]$.

\section{Statistical analysis}

Comparative statistical analyses among the groups were performed using SAS 4.1 (SAS Institute Inc., Cary, NC, USA). Factors potentially presenting the severity of acute appendicitis were assessed using one-way analysis of variance and included the WBC, segs, bands, AST, ALT, total bilirubin, SIRS score and symptom duration. For the multivariate analysis with logistic regression, the four groups were dichotomized into nonperforated (groups 1 and 2) and perforated (groups 3 and 4 ) groups, and the data were evaluated using the chi-square test. The results are presented as adjusted odds ratios (ORs) for a 95\% confidence interval (CI). Data are reported as means and standard deviations unless otherwise specified. All analyses were two-sided, with significance set at less than 0.05 .

\section{RESULTS}

\section{Clinical features}

Among the 1,195 patients that underwent an appendectomy due to acute appendicitis, 614 patients were men $(51.38 \%)$ and 581 were women (48.61\%). Statistically, all 4 groups showed significant differences regarding gender, mean age, symptom duration, hospitalization days and complication incidence. The durations of mean hospitalization and symptom were 4.27 days and 1.72 days, respectively. The total number of patients who had postoperative complications was 61 (5.1\%). The incidence rates of complications in the nonperforated (groups 1 and 2) and the perforated (groups 3 and 4 ) groups were $4.11 \%$ and $8.98 \%$, respectively (Table 2 ).

Table 2. Clinical characteristics

\begin{tabular}{|c|c|c|c|c|c|c|}
\hline Characteristic & Group $1(n=218)$ & Group $2(n=732)$ & Group $3(n=48)$ & Group $4(n=197)$ & Total $(n=1,195)$ & P-value \\
\hline Sex & & & & & & 0.0002 \\
\hline Male & $91(14.8)$ & $371(60.4)$ & $27(4.4)$ & $125(20.4)$ & $614(100)$ & \\
\hline Male:female & $1: 1.39$ & $1: 0.97$ & $1: 0.78$ & $1: 0.58$ & $1: 0.95$ & \\
\hline Age (yr) & $26.61 \pm 14.65$ & $31.09 \pm 16.83$ & $33.88 \pm 18.42$ & $37.76 \pm 22.02$ & $31.48 \pm 17.50$ & $<0.0001$ \\
\hline Hospital day (day) & $3.92 \pm 2.93$ & $3.69 \pm 1.50$ & $5.17 \pm 2.94$ & $6.59 \pm 5.19$ & $4.27 \pm 2.78$ & $<0.0001$ \\
\hline Complication incidence (\%) & $7(3.2)$ & $32(4.4)$ & $3(6.3)$ & $19(9.6)$ & $61(5.1)$ & 0.0121 \\
\hline
\end{tabular}

Sx., Symptom.

Values are presented as number (\%) or mean $\pm \mathrm{SD}$. 
Table 3. Preoperative laboratory parameters

\begin{tabular}{lcccccc}
\hline Parameter & Group $1(\mathrm{n}=218)$ & Group 2 $(\mathrm{n}=732)$ & Group 3 $(\mathrm{n}=48)$ & Group 4 $(\mathrm{n}=197)$ & Total $(\mathrm{n}=1,195)$ & P-value \\
\hline WBC $(/ \mu \mathrm{L})$ & $10,855.14 \pm 3,781.43$ & $13,454.01 \pm 4,421.70$ & $14,868.54 \pm 3,769.55$ & $14,760.30 \pm 5,585.15$ & $13,252.07 \pm 4,505.51$ & $<0.0001$ \\
Seg (\%) & $70.10 \pm 12.14$ & $77.84 \pm 10.44$ & $83.03 \pm 6.89$ & $81.73 \pm 8.16$ & $77.28 \pm 10.33$ & $<0.0001$ \\
Band (\%) & $n=3$, & $n=11$, & $n=6$, & $n=15$, & $n=35$, & 0.7764 \\
& $2.33 \pm 1.53$ & $2.23 \pm 1.03$ & $1.41 \pm 0.92$ & $2.60 \pm 3.27$ & $2.26 \pm 2.34$ & $20.53 \pm 8.67$ \\
AST (IU/L) & $21.49 \pm 11.43$ & $20.05 \pm 7.60$ & $19.88 \pm 8.31$ & $21.38 \pm 8.97$ & 0.0715 \\
ALT (IU/L) & $20.94 \pm 23.84$ & $19.62 \pm 20.82$ & $18.75 \pm 11.04$ & $20.06 \pm 13.36$ & $19.90 \pm 20.09$ & 0.8264 \\
TB (mg/dL) & $0.70 \pm 0.45$ & $0.83 \pm 0.46$ & $1.05 \pm 0.48$ & $1.02 \pm 0.54$ & $0.85 \pm 0.47$ & $<0.0001$ \\
SIRS score & $0.82 \pm 0.87$ & $1.04 \pm 0.87$ & $1.48 \pm 0.95$ & $1.43 \pm 1.06$ & $1.08 \pm 0.91$ & $<0.0001$ \\
\hline
\end{tabular}

Values are presented as mean $\pm \mathrm{SD}$.

WBC, white blood cell; Seg, segmented neutrophil; Band, banded neutrophil; AST, aspartate aminotransferase; ALT, alanine aminotransferase; TB, total bilirubin; SIRS systemic inflammatory response syndrome.

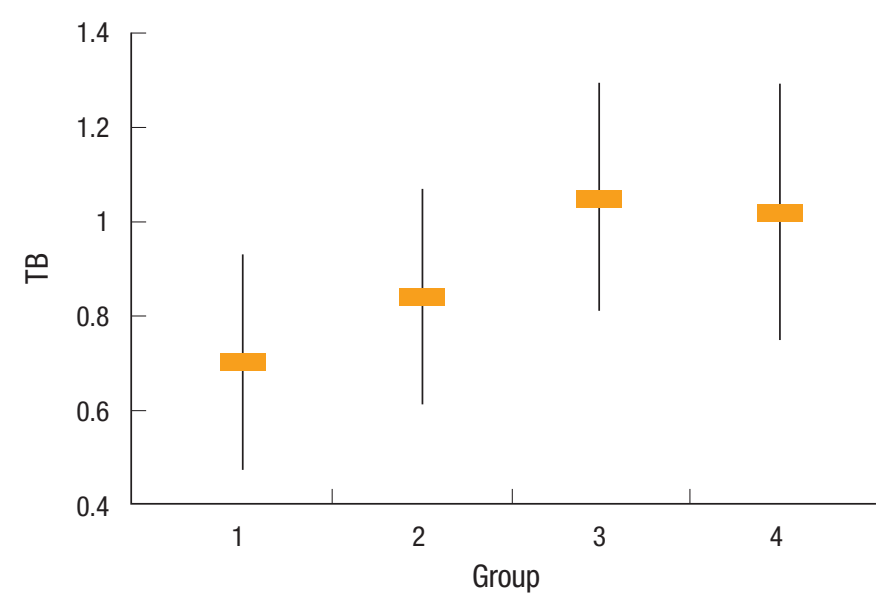

Fig. 1. Distribution of total bilirubin (TB) according to pathologic group.

\section{Surgical methods and preoperative laboratory parameters and univariate analysis}

More patients underwent a laparoscopic appendectomy than an open appendectomy, as 685 cases (57.32\%), underwent a laparoscopic appendectomy while 510 patients $(42.68 \%)$ underwent an open appendectomy. The WBC, segs, bands, AST, ALT, total bilirubin and SIRS score of each group were compared. Among them, WBC, segs, total bilirubin and SIRS were statistically significant (Table 3).

Among the 1,195 patients that underwent an appendectomy, the average WBC prior to the surgery was $13,252.07 / \mu \mathrm{L}$ (minimum, $1530 / \mu \mathrm{L}$; maximum, $38,720.00 / \mu \mathrm{L}$ ), and the differences between the four groups were statistically significant $(\mathrm{P}<0.0001)$. Within the differential count, the average segs was $77.28 \%$ (minimum, $30.20 \%$; maximum, $99.00 \%$ ), and the differences among the groups were statistically significant $(\mathrm{P}=0.0035)$.

The average of serum total bilirubin was $0.849 \mathrm{mg} / \mathrm{dL}$ (minimum, $0.050 \mathrm{mg} / \mathrm{dL}$; maximum, $4.310 \mathrm{mg} / \mathrm{dL}$ ), and statistically significant differences existed among the groups $(\mathrm{P}<0.0001)$. Among
Table 4. Logistic regression of multivariate parameters with adjusted odds ratio

\begin{tabular}{lccr}
\hline & Odds ratio & $\begin{array}{c}95 \% \text { Confidence in- } \\
\text { terval }\end{array}$ & P-value \\
\hline Age & 1.028 & $1.019-1.037$ & $<0.0001$ \\
Gender & 0.628 & $0.460-0.858$ & 0.0033 \\
WBC & 1.000 & $1.000-1.000$ & 0.0045 \\
Seg & 1.003 & $0.998-1.008$ & 0.2083 \\
TB & 1.772 & $1.320-2.379$ & 0.0001 \\
SIRS & 1.583 & $1.313-1.908$ & $<0.0001$ \\
\hline
\end{tabular}

WBC, white blood cell; Seg, segmented neutrophil; TB, total bilirubin; SIRS, systemic inflammatory response syndrome.

the 1,195 patients, patients that had a normal serum total bilirubin were 985 (82.42\%) without hyperbilirubinemia and 211 patients (17.66\%) with hyperbilirubinemia. Among the 211 patients, 17 were from group 1 (8.06\%), 116 were from group 2 (54.98\%), 16 were from group $3(7.58 \%)$ and 62 were from group $4(29.38 \%)$. The mean total bilirubin values were $0.7 \mathrm{mg} / \mathrm{dL}, 0.83 \mathrm{mg} / \mathrm{dL}, 1.05$ $\mathrm{mg} / \mathrm{dL}$, and $1.02 \mathrm{mg} / \mathrm{dL}$, respectively. The differences between the nonperforated (group A) and the perforated group (group B) were statistically significant $(\mathrm{P}<0.0001)$ (Fig. 1$)$.

\section{SIRS score}

The total number of patient with a SIRS score over 2 was 96 (8.0\%). Among them, patients with a SIRS score of 3 were 79 (6.61\%), and patients with a SIRS score of 4 were 17 (1.42\%). Among the patients with SIRS score $>2,12$ were from group $1(1.01 \%), 44$ were from group 2 (3.68\%), 7 were from group $3(0.58 \%)$, and 33 were from group 4 (2.66\%). In the statistical analysis using the two-by-K-type chi-square test, the results showed statistically significant differences among the groups $(\mathrm{P}<0.0001)$.

\section{Multivariate analysis}

After recategorizing groups 1 and 2 as a "nonperforated appendi- 


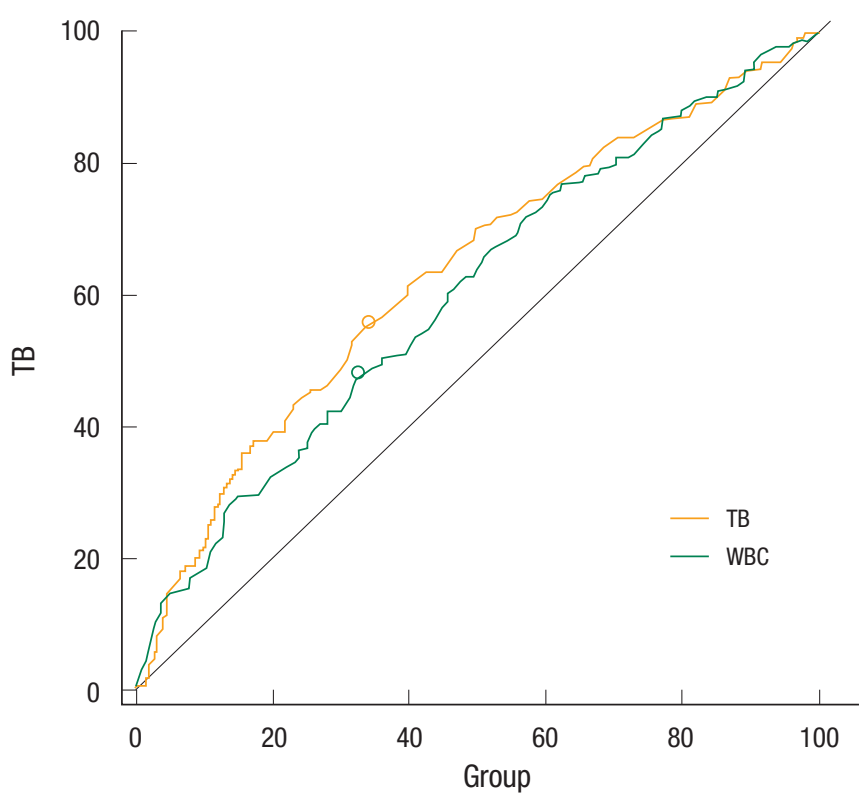

Fig. 2. Receiver operating characteristic curve analysis for bilirubin and white blood cell (WBC). TB, total bilirubin.

citis (A)" group and groups 3 and 4 as a "perforated appendicitis (B)" group, we performed a multivariate analysis by using an adjusted logistic regression on the variables that had shown statistical significance in the univariate analysis. As a result, total bilirubin (OR, 1.772; 95\% CI, 1.320 to 2.379) and SIRS (OR, 1.583; 95\% CI, 1.313 to 1.908 ) score were statistically significant in group B, but not in group A; total bilirubin was very significant in identifying perforated appendicitis (Table 4). According to the receiver operating characteristic (ROC) curve, the cut-off value of total bilirubin was $0.85 \mathrm{mg} / \mathrm{dL}$, and the area under the ROC curve (AUC) was 0.636; however, the AUC of the WBC was 0.604 (Fig. 2).

\section{DISCUSSION}

The incidence of acute appendicitis varies, but it is highly prevalent, occurring from in 7 to 22 out of 10,000 people [22, 23]. Whereas nonperforated acute appendicitis can be cured by an appendectomy without a long recovery period, perforated appendicitis or suppurative appendicitis can cause various complications that can result in life-threatening conditions [24]. Recent developments in the diagnosis of acute appendicitis with the assistance of radiological tools such as ultrasonography and CT have reduced the rate of negative appendectomies. Although the reported diagnostic accuracy of sonography varies depending on the patient population studied, a meta-analysis showed an overall sonographic sensitivity of $85 \%$ and a specificity of $92 \%$ [25]. The diagnostic utility of sonography for acute appendicitis has been emphasized and widely accepted especially for the pediatric and the pregnant patient groups [26]. Because of the development of helical CT, the effectiveness and the accuracy of diagnosing appendicitis have al- ready overcome the limitation of sonography, with sensitivities of 90 to $99 \%$ and specificities of 91 to $99 \%[5,6,27]$. However, a recent analysis by Pritchett et al. [28] showed that the increasing use of CT scanning in acute appendicitis increases the cost of care and the staying time in the emergency department, and delays the time to surgery. Because physical examinations and laboratory tests are still acknowledged as being of the utmost importance in the diagnostic process [29], we tried to find key laboratory tests that would allow us to anticipate the severity of acute appendicitis.

On the univariate analysis, for the total 1,196 patients, which is the largest sample ever reported to date, the usual laboratory tests, such as WBC, segs and total bilirubin, showed significant differences between the severity groups. Among these laboratory parameters, only bilirubin showed statistical significance in the multivariate regression. Its significant role in severe acute appendicitis was equivalent to the SIRS score, which is a combined laboratory and physical exam parameter.

Miller and Irvine [30] first reported that jaundice was common in patients with severe appendicitis. Recently, Sand et al. [16] reported a relatively high incidence of hyperbilirubinemia (24.9\%) from an analysis of 538 acute appendicitis patients, of whom 50.7\% were verified as having perforated appendicitis. Our data showed a relatively lower incidence of hyperbilirubinemia (17.64\%), as well as perforation (36.97\%), among the appendicitis patients. This may have influenced the result that our optimal sum of sensitivity (55.92\%) and specificity (66.11\%) at a cut-off level of greater than $0.85 \mathrm{mg} / \mathrm{dL}$ is relatively low compared to Miller's result. For an adjusted OR of 1.772 (95\% CI, 1.320 to 2.379), which included sex and age as independent variables, our result showed high diagnostic values as predictive factors for recognizing perforated appendicitis. This outcome is similar to those of other recent studies $[15,31]$, although there are some discrepancies in how to exactly divide the perforation and nonperforation groups. In our study, we categorized the patients into four groups according to the conventional pathological findings in order to test each laboratory parameter [19]; then, we simplified those groups in two groups (i.e., perforated and nonperforated) because gangrenous or necrotic appendicitis can belong to the perforation group in terms of clinical severity.

Concerning the pathophysiology of hyperbilirubinemia in acute appendicitis, there are some hypotheses. It is well accepted that a bacterial infection may play an important role as it disrupts the production and flow of bile, causing hyperbilirubinemia. This kind of pro-inflammatory cytokine and nitric-oxide-triggered cholestasis [32] can be found not only in perforated appendicitis but also in a general gastrointestinal perforation, which is associated with a poor prognosis [18]. The total bilirubin increases as the infection within the abdominal cavity becomes more severe. In the case of acute appendicitis, the infection is more severe when it is gangrenous or perforated, thereby strengthening the theory that hyperbilirubinemia may be helpful in detecting perforated appendicitis. The overall complication rate of appendectomy depends upon the 
status of the appendix at the time it is removed. In our study the average postappendectomy complication rate was $5.1 \%$, which is similar to the data in the literature [33]. In the cases of perforated appendicitis, the risk of complication increases drastically, and this is also correlated to the incidence difference between the nonperforated group and the perforated group ( $4.1 \%$ vs. $8.9 \%)$.

In terms of the diagnostic role of hyperbilirubinemia in acute appendicitis, the SIRS score is also mentioned for its positive predictive value $[15,21]$. Because SIRS is a clinical criterion reflecting inflammatory disease, it is thought that the SIRS score might correlate with hyperbilirubinemia, which might be suggestive of the severity of the acute appendicitis. In fact, from our multivariate analysis, the SIRS score and hyperbilirubinemia are significant predictors of appendiceal perforation whereas the WBC and segs, which are frequently used as markers of acute inflammation, were not statistically significant. However, as the SIRS score itself is a sum of four figures with four criteria, using it as an independent variable would be inappropriate.

From the large-scale population that underwent surgery in our single institution, this study confirms the predictive value of hyperbilirubinemia in acute appendicitis patients. This result might be very helpful in the decision to operate and in diagnosing the severity of the disease.

\section{CONFLICT OF INTEREST}

No potential conflict of interest relevant to this article was reported.

\section{REFERENCES}

1. Seal A. Appendicitis: a historical review. Can J Surg 1981;24: 427-33.

2. Amyand C. Of an inguinal rupture, with a pin in the appendix caeci encrusted with stone: some observations on wounds in the guts. Philos Trans R Soc Lond 1736;39:329-36.

3. Franke C, Bohner H, Yang Q, Ohmann C, Roher HD. Ultrasonography for diagnosis of acute appendicitis: results of a prospective multicenter trial. Acute Abdominal Pain Study Group. World J Surg 1999;23:141-6.

4. Poortman P, Lohle PN, Schoemaker CM, Oostvogel HJ, Teepen $\mathrm{HJ}$, Zwinderman KA, et al. Comparison of CT and sonography in the diagnosis of acute appendicitis: a blinded prospective study. AJR Am J Roentgenol 2003;181:1355-9.

5. Cakirer S, Basak M, Colakoglu B, Bankaoglu M. Diagnosis of acute appendicitis with unenhanced helical CT: a study of 130 patients. Emerg Radiol 2002;9:155-61.

6. Lane MJ, Liu DM, Huynh MD, Jeffrey RB Jr, Mindelzun RE, Katz DS. Suspected acute appendicitis: nonenhanced helical CT in 300 consecutive patients. Radiology 1999;213:341-6.

7. Alvarado A. A practical score for the early diagnosis of acute appendicitis. Ann Emerg Med 1986;15:557-64.

8. Douglas CD, Macpherson NE, Davidson PM, Gani JS. Randomised controlled trial of ultrasonography in diagnosis of acute appendicitis, incorporating the Alvarado score. BMJ 2000;321:919-22.

9. Owen TD, Williams H, Stiff G, Jenkinson LR, Rees BI. Evaluation of the Alvarado score in acute appendicitis. J R Soc Med 1992;85: $87-8$.

10. Lamparelli MJ, Hoque HM, Pogson CJ, Ball AB. A prospective evaluation of the combined use of the modified Alvarado score with selective laparoscopy in adult females in the management of suspected appendicitis. Ann R Coll Surg Engl 2000;82:192-5.

11. de Castro SM, Unlu C, Steller EP, van Wagensveld BA, Vrouenraets $\mathrm{BC}$. Evaluation of the appendicitis inflammatory response score for patients with acute appendicitis. World J Surg 2012;36: 1540-5.

12. Andersson M, Andersson RE. The appendicitis inflammatory response score: a tool for the diagnosis of acute appendicitis that outperforms the Alvarado score. World J Surg 2008;32:1843-9.

13. Ohle R, O'Reilly F, O'Brien KK, Fahey T, Dimitrov BD. The Alvarado score for predicting acute appendicitis: a systematic review. BMC Med 2011;9:139.

14. Emmanuel A, Murchan P, Wilson I, Balfe P. The value of hyperbilirubinaemia in the diagnosis of acute appendicitis. Ann R Coll Surg Engl 2011;93:213-7.

15. Estrada JJ, Petrosyan M, Barnhart J, Tao M, Sohn H, Towfigh S, et al. Hyperbilirubinemia in appendicitis: a new predictor of perforation. J Gastrointest Surg 2007;11:714-8.

16. Sand M, Bechara FG, Holland-Letz T, Sand D, Mehnert G, Mann B. Diagnostic value of hyperbilirubinemia as a predictive factor for appendiceal perforation in acute appendicitis. Am J Surg 2009;198:193-8.

17. Ger R. Hyperbilirubinemia due to intraperitoneal sepsis. N Y State J Med 1972;72:2407-13.

18. Nishida T, Fujita N, Megawa T, Nakahara M, Nakao K. Postoperative hyperbilirubinemia after surgery for gastrointestinal perforation. Surg Today 2002;32:679-84.

19. Crawford JM. The gastrointestinal tract. In: Cotran RS, Kumar V, Collins T, Robbins SL, editors. Robbins pathologic basis of disease. 6th ed. Philadelphia: Saunders; 1999. p. 839-40.

20. Gregoric P, Sijacki A, Stankovic S, Radenkovic D, Ivancevic N, Karamarkovic A, et al. SIRS score on admission and initial concentration of IL-6 as severe acute pancreatitis outcome predictors. Hepatogastroenterology 2010;57:349-53.

21. Nozoe T, Matsumata T, Sugimachi K. Significance of SIRS score in therapeutic strategy for acute appendicitis. Hepatogastroenterology 2002;49:444-6.

22. Lee JH, Park YS, Choi JS. The epidemiology of appendicitis and appendectomy in South Korea: national registry data. J Epidemiol 2010;20:97-105.

23. Buckius MT, McGrath B, Monk J, Grim R, Bell T, Ahuja V. Changing epidemiology of acute appendicitis in the United States: study period 1993-2008. J Surg Res 2012;175:185-90.

24. Fike FB, Mortellaro VE, Juang D, Sharp SW, Ostlie DJ, St Peter SD. The impact of postoperative abscess formation in perforated 
appendicitis. J Surg Res 2011;170:24-6.

25. Orr RK, Porter D, Hartman D. Ultrasonography to evaluate adults for appendicitis: decision making based on meta-analysis and probabilistic reasoning. Acad Emerg Med 1995;2:644-50.

26. Barloon TJ, Brown BP, Abu-Yousef MM, Warnock N, Berbaum KS. Sonography of acute appendicitis in pregnancy. Abdom Imaging 1995;20:149-51.

27. Schuler JG, Shortsleeve MJ, Goldenson RS, Perez-Rossello JM, Perlmutter RA, Thorsen A. Is there a role for abdominal computed tomographic scans in appendicitis? Arch Surg 1998;133:373-6.

28. Pritchett CV, Levinsky NC, Ha YP, Dembe AE, Steinberg SM. Management of acute appendicitis: the impact of CT scanning on the bottom line. J Am Coll Surg 2010;210:699-705.

29. Kalliakmanis V, Pikoulis E, Karavokyros IG, Felekouras E, Morfa- ki P, Haralambopoulou G, et al. Acute appendicitis: the reliability of diagnosis by clinical assessment alone. Scand J Surg 2005;94: 201-6.

30. Miller DF, Irvine RW. Jaundice in acute appendicitis. Lancet 1969; 1:321-3.

31. Atahan K, Ureyen O, Aslan E, Deniz M, Cokmez A, Gur S, et al. Preoperative diagnostic role of hyperbilirubinaemia as a marker of appendix perforation. J Int Med Res 2011;39:609-18.

32. Geier A, Fickert P, Trauner M. Mechanisms of disease: mechanisms and clinical implications of cholestasis in sepsis. Nat Clin Pract Gastroenterol Hepatol 2006;3:574-85.

33. Hale DA, Molloy M, Pearl RH, Schutt DC, Jaques DP. Appendectomy: a contemporary appraisal. Ann Surg 1997;225:252-61. 